\title{
First Successful Separation of Craniopagus Twins in India-Plastic Surgical Considerations
}

\author{
Maneesh Singhal ${ }^{1}$ Shanmuganathan Raja Sabapathy ${ }^{2}$ Deepak Gupta ${ }^{3}$ A. K. Mahapatra ${ }^{4}$ \\ Shashank Chauhan ${ }^{10}$ Raja Tiwari ${ }^{10}$ Hari Venkatramani ${ }^{2}$ Shweta Kedia ${ }^{3}$ Shivangi Saha10 \\ Shamendra Anand Anand Sahu $\left.{ }^{5(}\right)$ Suvashis Dash ${ }^{10}$ Megha Sodhi ${ }^{10}$
}

1 Department of Plastic Reconstructive and Burns Surgery, Burns \& Plastic Surgery Block, All India Institute of Medical Sciences New Delhi, India

${ }^{2}$ Division of Plastic, Hand, Reconstructive Microsurgery and Burns, Ganga Hospital, Coimbatore, Tamil Nadu, India

${ }^{3}$ All India Institute of Medical Sciences, New Delhi, India

${ }^{4}$ SOA University, Odisha, India

${ }^{5}$ Department of Plastic Surgery, All India Institute of Medical Sciences Raipur, Chhattisgarh, India

Indian J Plast Surg 2022;55:36-44
Address for correspondence Maneesh Singhal, MBBS, MS, MCh., FACS, FRCS, All India Institute of Medical Sciences (AlIMS), Room no. 5014C, 5th Floor, Teaching Block, New Delhi, 110029, India (e-mail: drmaneesh@gmail.com).

\author{
Abstract \\ Keywords \\ - Craniopagus \\ separation \\ - tissue expander \\ - conjoint twins \\ - trapezius \\ myocutaneous flaps \\ - dermal matrices \\ - allograft
}

Separation of total vertical craniopagus with shared venous sinuses poses multiple challenges. Provision of soft-tissue cover to the exposed brains at the time of total separation is one of them, due to the large size of the defect and paucity of local tissues. Staged separation of twins is advised with partial venous and parenchymal disconnection in the first stage and total separation in the second stage. Tissue expanders are inserted in the first stage, and second stage planned to coincide with the period of adequate expansion. In the child being reported, emergency second stage was done due to the deteriorating general condition of the children. Left with inadequate expanded skin, the critical defect in a twin was managed with bilateral trapezius myocutaneous flaps. High ionotropic support of the postoperative period resulted in superficial necrosis of the flap, which was managed by debridement, allograft application and autograft later. Both twins had well-healed wounds by 3 months.

\section{Introduction}

Craniopagus twins are conjoint twins who are embryologically joined at the cranial neuropore region (pagus meaning "fixed") in which there is no involvement of the face, umbilicus or the heart. ${ }^{1}$ Craniopagus twinning is the rarest of the conjoint twins ( 0.6 per million births) with a female to male preponderance of $4: 1{ }^{2}$ Conjoint twins rarely survive the first year of life. About 40 to $60 \%$ are stillborn, and out of those born alive, only approximately $35 \%$ survive their first day of

published online

February 22, 2022
DOI https://doi.org/ $10.1055 / \mathrm{s}-0041-1740406$ ISSN $0970-0358$. life. $^{3}$ Due to the rarity of the condition, only a handful of surgeons around the world have experience of the surgical separation of craniopagus twins, and there is no standard protocol. However, a few basic principles have emerged to assist in formulating a "battle plan."

"Success" in craniopagus separation is described as the survival of both the twins at 30 days after separation. ${ }^{2}$ The mortality after craniopagus separation was more than $60 \%$ before $1974 .{ }^{4}$ Harvey et al, in their systematic review, reported 17 attempts of craniopagus twin separations in

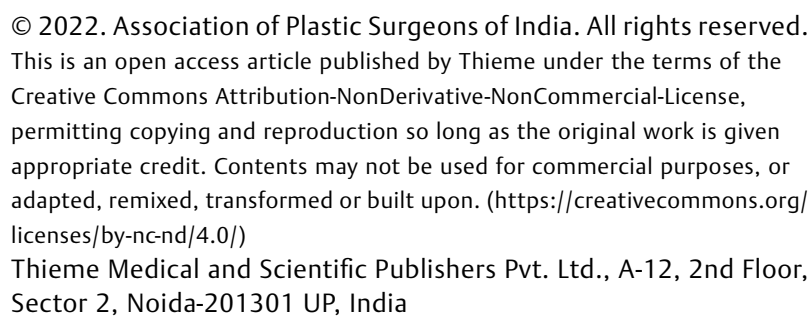


the 20-year period from 1995 to 2015 . One twin died in 5 (29\%) of these cases and both twins died in 1 (6\%) case, resulting in a total mortality rate of $21 \%$ within 30 days of attempted separation.

Craniopagus twins have a variable amount of fusion involving the skin, subcutaneous tissue, bony calvarium, leptomeninges, brain parenchyma, and venous sinuses. However, the foramen magnum, face, and vertebrae are not involved. When the extent of fusion increases, separation becomes difficult with worsening of the neurological outcome. Plastic surgeons play a critical role in providing skin and soft-tissue cover to the exposed brain and the calvaria during the craniopagus separation. The extensive size of the defects, the need to cover with flaps rather than skin grafts, and the immediacy of the requirement at the end of what is already a long procedure are the challenges faced by the plastic surgery team. ${ }^{5}$ We report the plastic surgical considerations and the lessons learned during India's first successful separation of craniopagus twins.

\section{Case Report}

Commonly known as the "AIIMS twins," twin J and twin B, belonging to a remote village in the state of Odisha, were admitted to the All India Institute of Medical Sciences (AIIMS), New Delhi, under neurosurgery care on July 13 , 2017, when they were 2 years and 3 months of age (-Fig. 1 ). The commonly used classifications are the O'Connell classification ${ }^{6}$ and the Stone and Goodrich ${ }^{7}$ classification systems. Our twins belonged to the O'Connell type 3 total vertical variant. The twins shared a single oblique sinus in place of superior sagittal sinus, which drained the cerebral cortices of both the twins.

"Team Craniopagus" was formed to plan for their surgical separation. Led by neurosurgeons (D.G., A.K.M.), the team members were from the departments of Neurosurgery, Pediatric Critical Care, Neuro-Anesthesia, Cardiac-Anesthesia, Plastic and Reconstructive Surgery, Pediatric Surgery, Pediatric Nephrology, Pediatric Cardiology, Neuro-Radiology and Neuro-physiotherapy and Neurosurgery Nursing staff.

The neurosurgical team planned a staged separation. In the first stage, partial venous and parenchymal separation

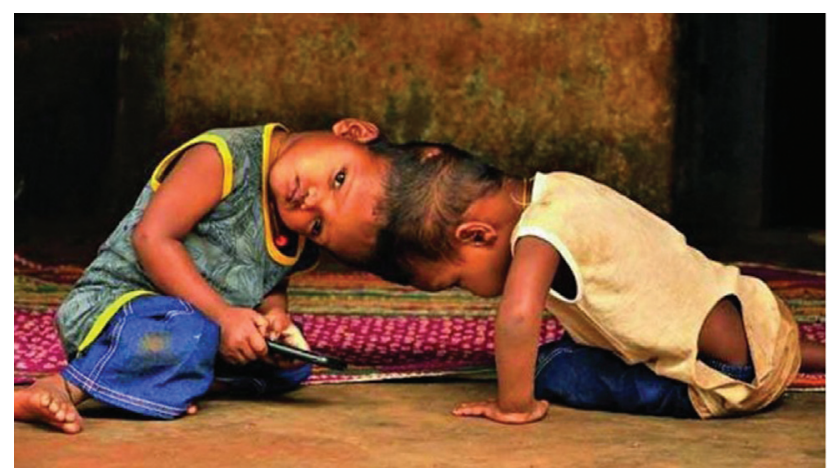

Fig. 1 The All-India Institute of Medical Sciences (AIIMS) twins. O'Connell type III total vertical craniopagus-Note the orientation of the heads and the body. The child with the full face seen is twin J. The child whose left ear is seen is twin B. were planned with complete separation in the second stage. Staged separation provides adequate time for the equilibration of venous drainage of the brain and time for the plastic surgery team to expand the skin to facilitate closure.

\section{Stage 1-Plastic Surgery Planning}

The possible challenges that would be encountered in stage 1 ( - Table 1) were discussed, and the following goals were set:

1. To provide adequate exposure for partial separation of the twins, taking care to avoid incisions that could compromise the vascularity of skin flaps during wound closure in the second stage (-Fig. 2 ).

2. To preserve as much pericranium as possible.

3. In case of any complication necessitating emergency separation of the twins, to be ready for salvage procedures, in order to provide wound cover to both or at least to the twin who had the better chance of survival.

Life-size 3D printed reconstructed models were procured (-Fig. 3). The models provided an idea of the magnitude of the postseparation skin defect. The skulls of the children were joined vertically with the cerebral cortex of one child going obliquely to the posterior fossa of the second child. This oblique lie of the brains significantly increased the surface area of the defect to be covered after separation.

The postseparation defect size was calculated to be approximately $250 \mathrm{~cm}^{2}$ for each child, with allowance made for the following variables: intraoperative and postoperative brain edema, sharp edges and relative height of bone cuts following craniotomy and the obliquity of the resultant defects. After making actual cuts on the 3D printed skull models, this area was calculated, separating them and then draping the defect with a cloth template. In small children, no single flap could address such a large area. It was decided to introduce tissue expanders during the first stage and gain tissue to cover the defect at the second stage.

We then planned the volume, dimensions, and site of expander placement. Based on the mathematical equation, ${ }^{8}$ for an area of 250 square $\mathrm{cm}$, a large expander of $700 \mathrm{~mL}$ and $11 \mathrm{~cm}$ height was required. As a single implant of that volume was unavailable, we planned to use two $300 \mathrm{~mL}$ cuboid-shaped tissue expanders and overinflate them. We then planned the site of placement of the expanders. The hair-bearing scalp that could have optimally been utilized was also the resting surface of both the twins. The risk of pressure injury forced us to look for other areas. We decided on both the occipitofrontal regions for insertion of tissue expanders, since the sites were away from the resting surface when the children were asleep and away from the craniotomy site and associated hardware (-Fig. 4). We planned tissue expanders placement at the end of the neurosurgical procedure in the first stage.

\section{The Stage 1-Surgical Procedure}

The plastic surgical team was involved at the incision stage, then descrubbed, and stayed through the whole procedure in 


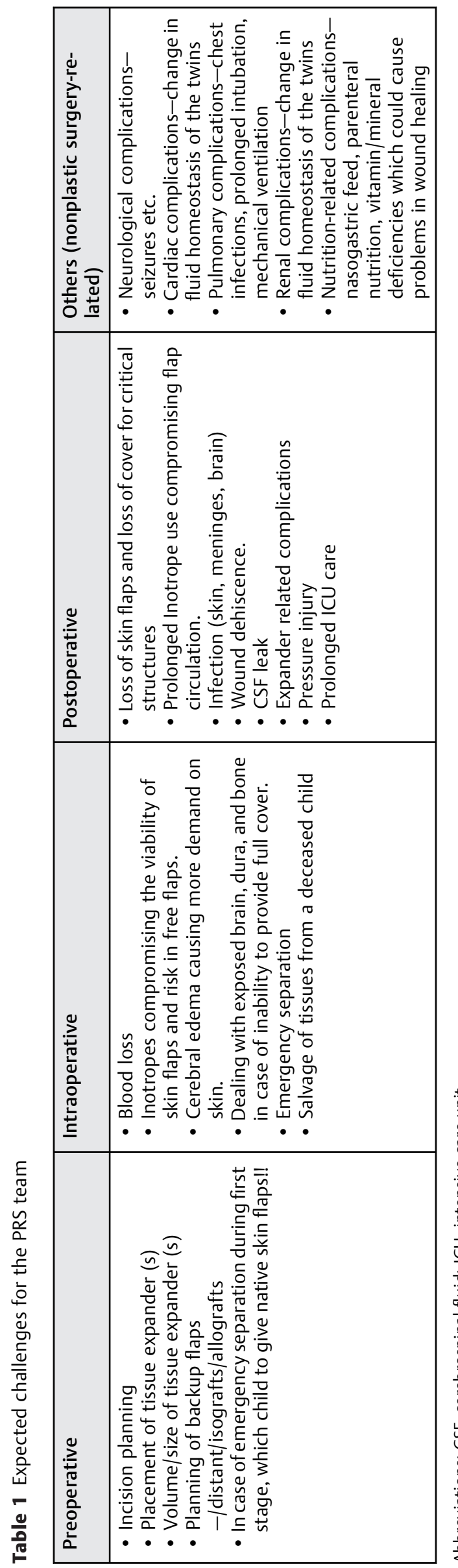

case an emergency separation was precipitated during any time in the first stage. An operating room was ready for the eventuality.

The neurosurgery team performed partial hemispheric disconnection and venous bypass in stage 1 . The children tolerated the procedure well and were deemed fit to undergo tissue expander placement. The plastic surgery team received a go-ahead from the neuroanesthesia team 18 hours after the first incision. Two $300 \mathrm{~mL}$ cuboid tissue expanders were placed with their ports over the respective temporal bone for easy localization (-Fig. 5). It was expected that the required expansion would take 14 to 16 weeks to complete and the second stage was timed accordingly.

\section{Postoperative Course (after 1st Stage)}

The suture line was healing well, and saline instillation in the tissue expanders was started on the 10th postoperative day (-Fig. 6). In the third week, the expander inserted in twin J leaked due to an inadvertent needle stick injury. This was a major complication since it required expander exchange. The children were scheduled for a magnetic resonance imaging (MRI) the week after, so it was decided to replace the expander during that anesthesia. The expander was replaced, and saline expansion was again started. Unfortunately, after few days of expansion, the suture line of the replaced expander showed signs of impending wound dehiscence, which was revised under local anesthesia while taking care not to puncture the expander again. In the meantime, we continued to expand the other tissue expander (inserted in twin B) with twice-weekly saline instillation. The expansion schedule fell 4 weeks behind schedule due to these two expander-related complications.

\section{Planning for the 2nd Stage}

The plastic surgery team created a 3D model of the skin and soft tissue to be placed over the 3D printed reconstructed models of the children's heads at the end of the proposed tissue expansion to simulate the expanded skin available and place the proposed incisions on it to see how the skin flaps would redrape once incisions were made in the second stage. Two cardboard boxes were used to simulate the tissue expanders and placed on the occipitofrontal regions of the models. The models were then wrapped in aluminum foil, roller bandage, and then multiple coats of liquid latex were painted over the bandage ( $\mathbf{F i g . ~} \mathbf{7}$ ) to simulate the possible final status of the scalp flaps in the children on completion of the proposed tissue expansion schedule

We planned to incorporate one superficial temporal artery in both the anterior scalp flaps which could be used as a microvascular-free flap recipient vessel. We raised the simulated skin flaps with the proposed incisions and attempted to redrape the flaps over the divided skull model. It was found that for twin J, it was possible to cover the brain with the help of expanded and native scalp flaps but would require skin grafts over the areas covered by pericranium. In twin B, a large defect in the occipital area of approximately 


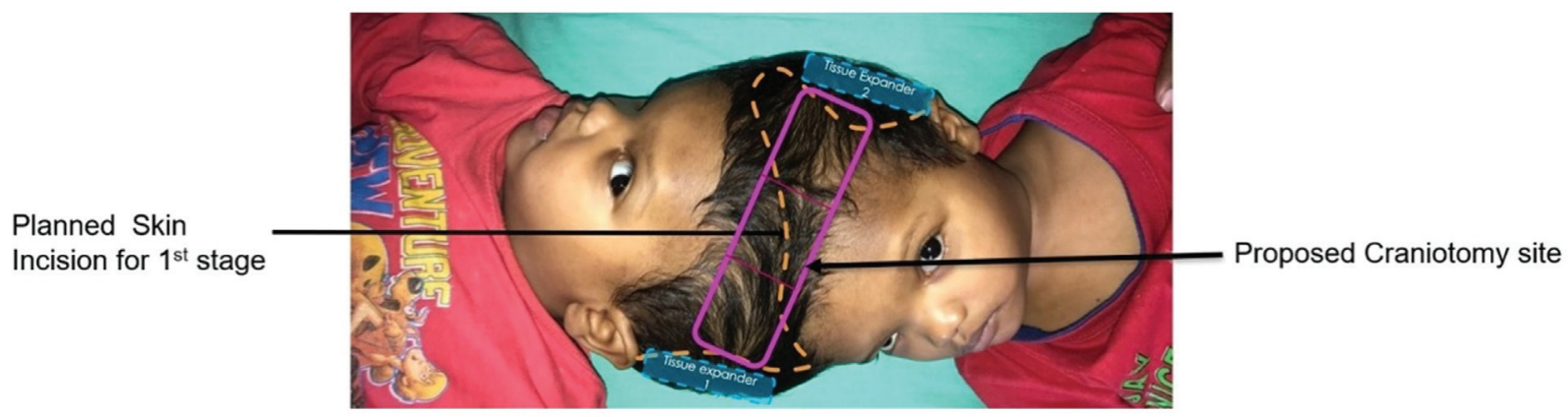

Fig. 2 Photograph showing anterior surface while the twins were lying down supine, the proposed skin incisions and the relationship to the craniotomy site.

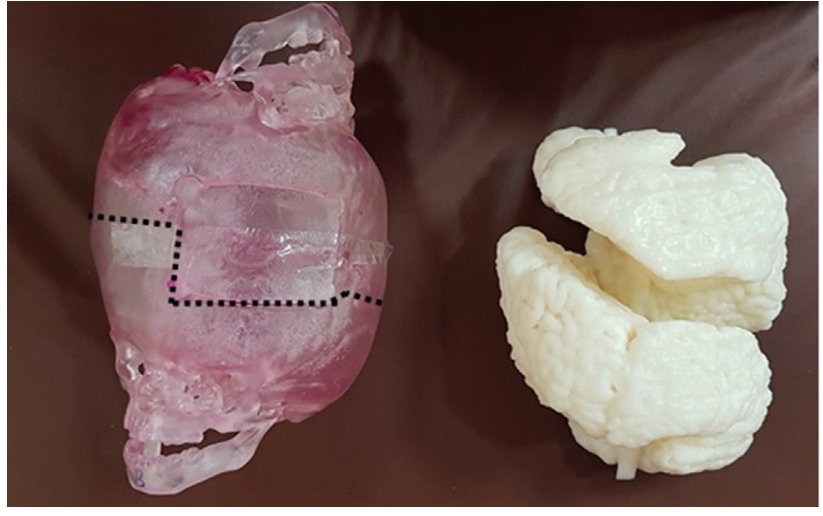

Fig. 3 3D printed skull and brain models, the dotted lines show the probable line of bone cut.
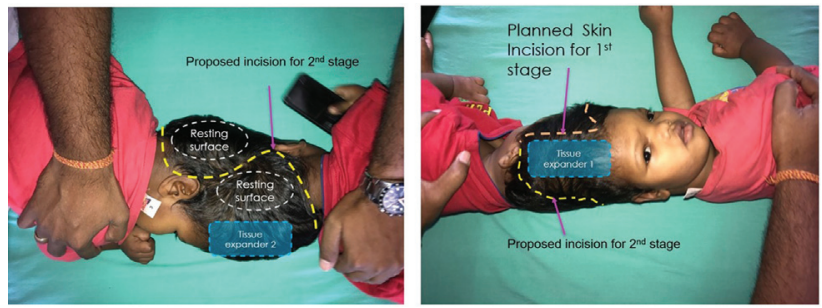

Fig. 4 Photograph showing posterior resting surface and proposed sites of tissue expanders placement.

150 square $\mathrm{cm}$ existed with possible calvarial defect and brain exposure, which would not be covered by any scalp flap and would require extra skin from elsewhere. This extra skin requirement in one child forced the plastic surgical team to investigate more complex options like microvascular-free tissue transfer or other regional flaps.

\section{Physiological Crisis leading to Early Separation}

When we were through approximately 7 weeks of tissue expansion for twin B and approximately 3 weeks of tissue expansion for twin J, the surgical teams were informed by the pediatric nephrologists and cardiologists that one child (twin B) was preferentially draining to the other $(\operatorname{twin} \mathrm{J})$, and a semiemergency separation seemed imminent. ${ }^{9}$ They

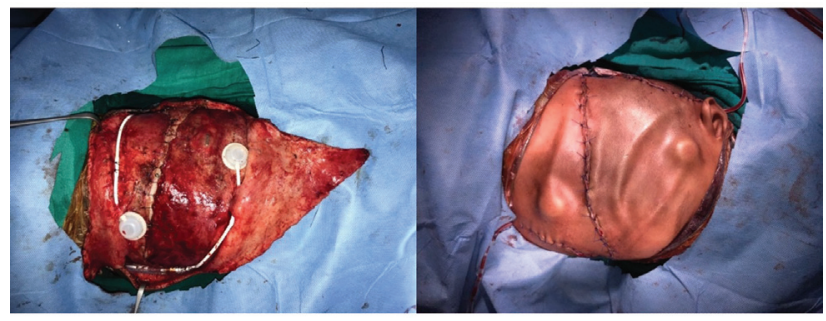

Fig. 5 Two tissue expanders were placed, and ports were positioned over the temporal regions for easy accessibility.

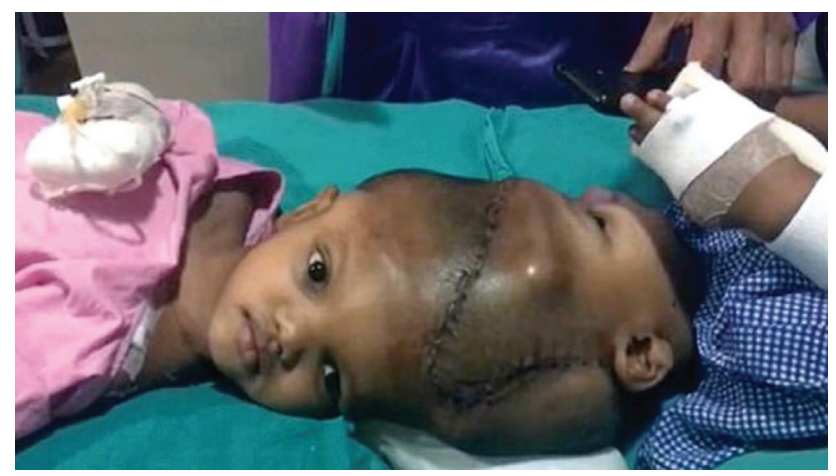

Fig. 6 Healing suture line and expanders in place.

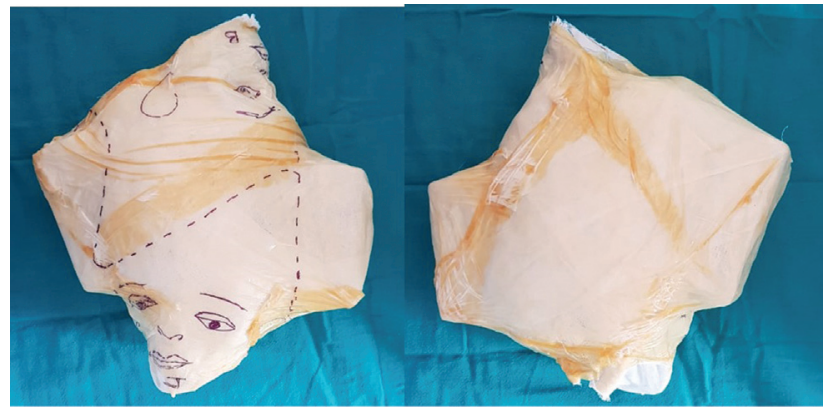

Fig. 7 Anterior and posterior surfaces of the 3D model showing the recreated skin and planned incisions (note the expanders in the occipito-frontal regions).

advised that the children should undergo separation as soon as possible, otherwise both children could die due to the recently diagnosed comorbidities. It caused severe concern since twin $\mathrm{J}$ had the native venous sinus and was 
thought to have better chances of survival but was suffering severe heart failure with only $20 \%$ ejection fraction.

The crisis brought fresh challenges to the plastic surgical team. First, we had not covered the required period of expansion. The hemodynamic complication precipitated emergency separation 8 weeks earlier. We were sure that we would fall short in providing postseparation skin cover in a big way. It also brought in questions with no simple answers. If one child died during the surgery, can grafts and flaps be harvested from that child to save the other child? Should we preferentially plan to give more native flaps than skin grafts to the child with presumed better chances of survival? Such questions raised not only technical but also ethical issues. Further, it was felt that after raising the skin flaps, the expanded skin could go for contraction during the possible 15 to 20 hours which would be taken by the neurosurgeons to complete the separation of the brain. We needed to think of some techniques to retain the gains made by tissue expansion, since the shrinkage of expanded scalp flaps was anticipated. $^{10}$

\section{The Separation}

After a series of discussions involving the whole "Team Craniopagus," it was decided that the children should undergo early separation due to the fast deterioration of the general condition. The incisions were made on the previously planned lines of expander placement. The plastic surgery team had come up with an idea of immediate intraoperative hyperinflation to prevent intraoperative skin retraction that could occur during the neurosurgical procedure. Two skin graft carriers, which are used in skin meshing, were cut into sizes equal to the base size of the tissue expanders, and multiple holes were drilled on their sides ( - Fig. 8). With that, sutures were taken to hold the tissue expander in place. The skin graft mesher plates provided a solid base against which expanders could be retained, and skin retraction prevented. During the procedure, intermittent saline injection was also continued monitoring skin capillary refill on pressure.

After complete separation, twin B was shifted to the adjacent theater for final closure, while twin J stayed in the same theater. The surgical procedure of separation was uneventful.

\section{Twin J}

Thirty minutes after separation, twin J developed air embolism and had an intraoperative cardiac arrest. The child was revived successfully by the anesthesia team, and we were permitted to proceed with the surgery for skin cover of the defects. By utilizing the native expanded scalp flaps and the pericranium, all the critical areas in twin J could be covered primarily. Split thickness skin grafts (STSG) were put over the pericranium (-Fig. 9).

\section{Twin B}

Twin B had a much bigger defect, and as expected, the defect in the occipital region was devoid of bone, with the brain hanging out of the calvarium needing support (-Fig. 10). The

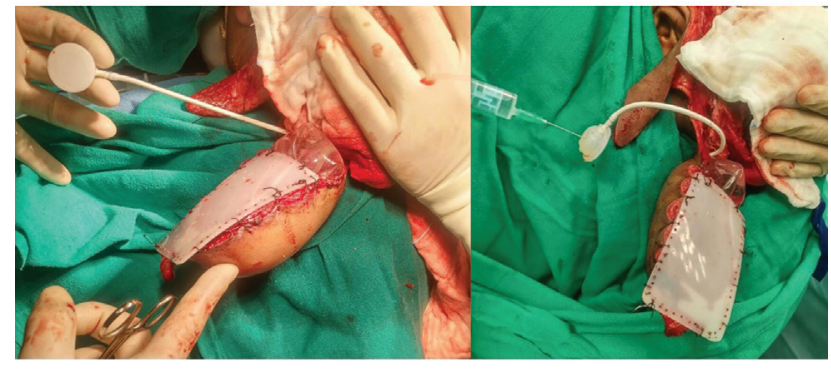

Fig. 8 Skin graft carriers were used as solid bases to keep tissue expanders in temporary pockets to prevent skin retraction.

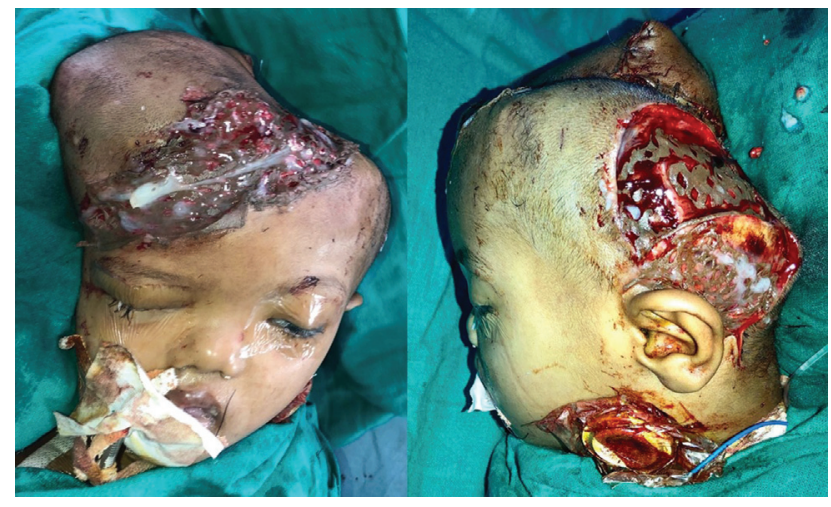

Fig. 9 Immediate postoperative photograph of twin J.

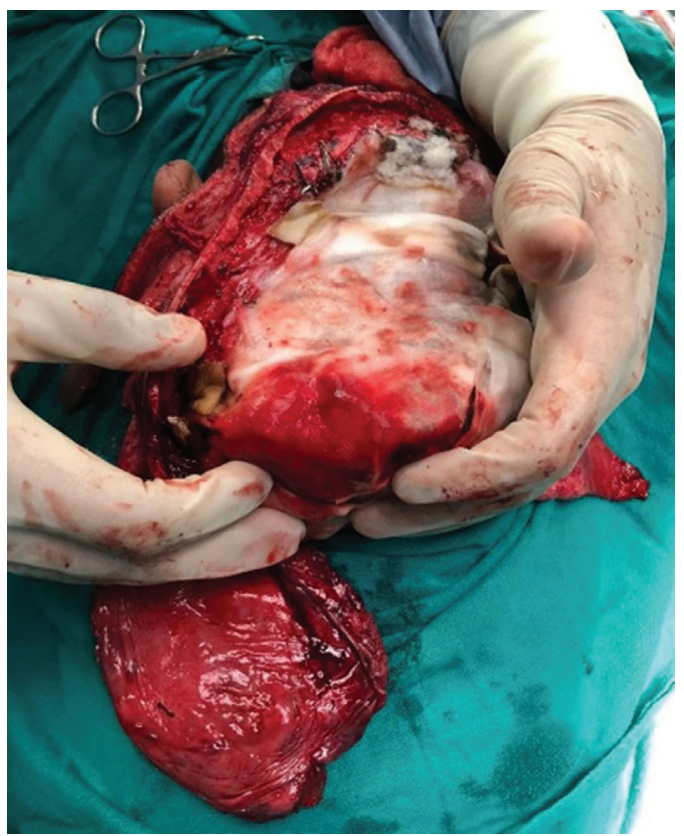

Fig. 10 Exposed posterior calvarium of twin B. Note the level of the occipital bone cuts.

expanded frontal scalp flap and the unexpanded lateral skin flaps covered the frontal and high parietal regions bilaterally. The bare brain was first covered posteriorly with a synthetic dural graft matrix. The defect measured $12 \times 12 \mathrm{~cm}$. No free flap would cover such a large defect. Further, the recipient's vessels were too far from the defect, making free flaps technically impossible. 


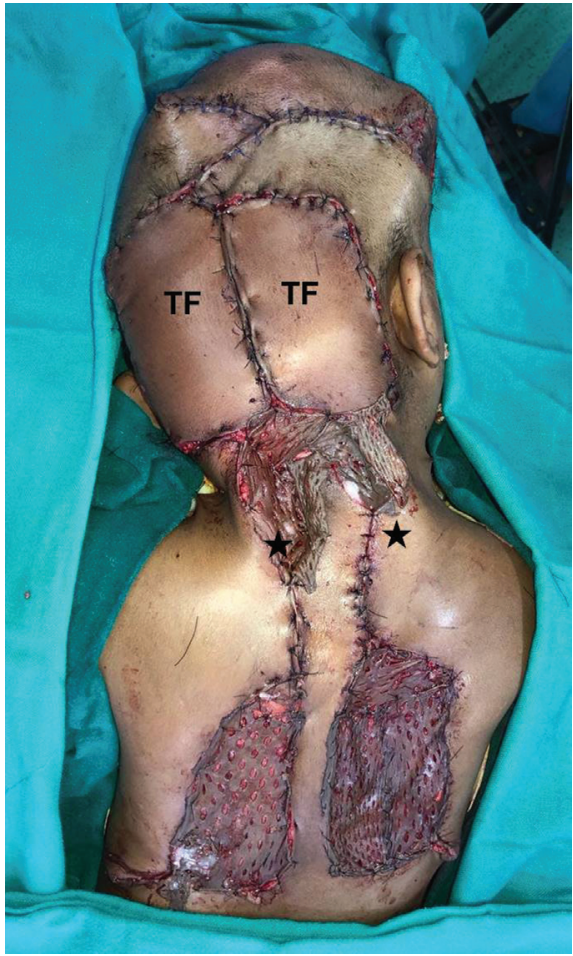

Fig. 11 Photograph showing final closure in twin B after bilateral trapezius myocutaneous flaps (TF). The denotes the pivot point of flap rotation.

On the table, it was decided to perform bilateral trapezius myocutaneous flaps. Two $12 \mathrm{~cm} \times 6.5 \mathrm{~cm}$ myocutaneous flaps were raised, keeping the distal limit of the muscle as the distal end of the flap. The skin island with the whole muscle was raised to the level of $C 7$, where the superior cervical artery of the thyrocervical trunk entered the trapezius. Basing that as the pivot point, the flaps were turned and sutured to the scalp flaps. Intraoperatively, both the flap edges showed good bright red subdermal bleed. Part of the pedicle and donor area were split skin grafted (-Fig. 11). The twins required high-ionotropic support for massive blood loss during the final stages of separation.

\section{Postoperative Course (After Complete Separation)}

\section{Twin J}

Due to intense peripheral vasoconstriction of prolonged triple inotropes support, the suture lines of the flaps showed discoloration. Marginal flap vascular compromise was managed nonoperatively. Also, there was a small area of $3 \times 3 \mathrm{~cm}$ in the left occipital region, where the bone got exposed. Multiple drill holes were made in the bone for the development of granulation tissue. Fortunately, there was no cerebrospinal fluid (CSF) leak in twin J. He underwent one more surgical procedure in which a protruding part of the right temporal bone cut edge was trimmed and a split skin graft was placed over the granulation tissue to enable complete wound healing (-Fig. 12).

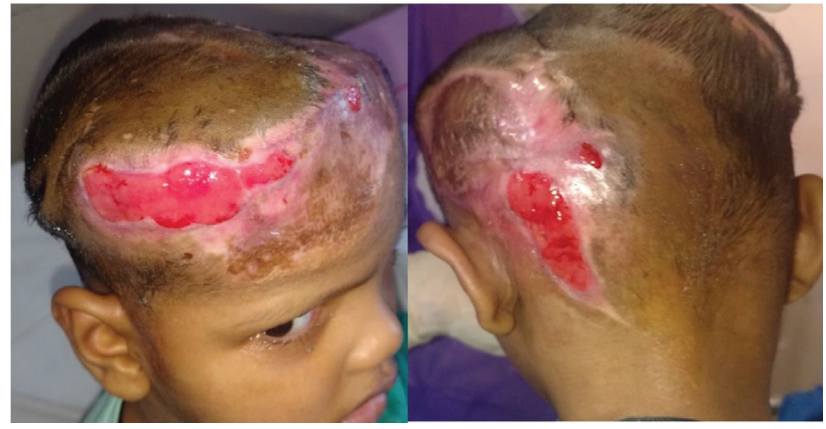

Fig.12 The twin J showing settling of the flaps and granulation tissue fit for grafting.

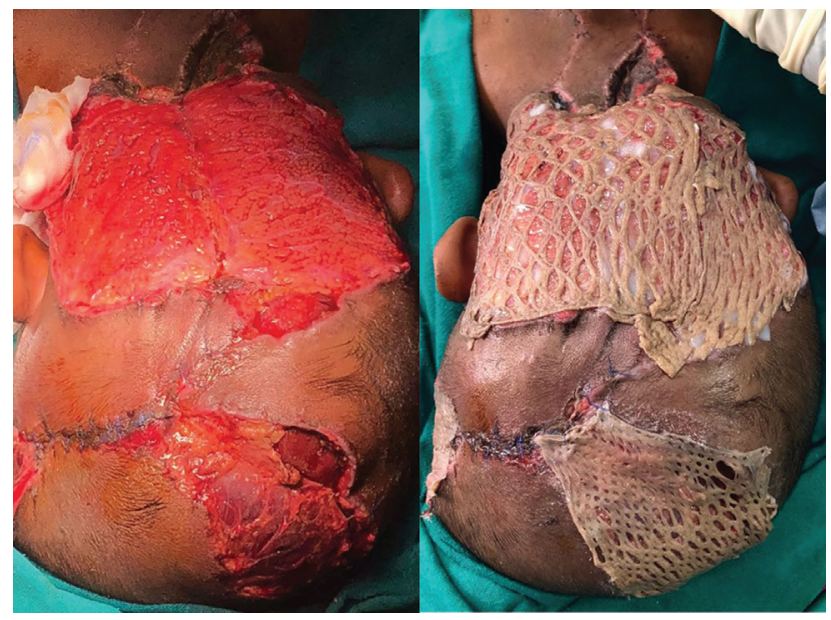

Fig. 13 Healthy tissue after debridement of the superficial necrosis of the skin component of the trapezius flaps and raw area on the vertex. Postdebridement covered with allograft.

\section{Twin B}

Twin B had been on triple inotropes for much longer time than twin J, and this affected the precariously viable flaps. The bilateral trapezius flaps, which we had raised to their limits, were showing signs of vascular compromise. The skin showed discoloration and was managed expectantly. When the skin formed an eschar, we took the child for debridement. Beneath the skin, the soft tissues appeared to be viable with signs of bleeding. To protect the viable tissue, skin allograft was applied as temporary cover, as there was still doubt about the viability, and there was a paucity of autograft (-Fig. 13). At this point, there was no CSF leak in twin B. Directly beneath was the posterior fossa, so a radical debridement was avoided.

But the soft tissue gave way, and there was complete wound dehiscence in twin B along with excessive CSF leakage and exposed brain tissue There was slough inside the ventricles and over the brain which was sequentially debrided and made ready for cover. After another round of allograft, the bed was ready to accept autograft.

\section{Outcome}

Twin J did not require any further procedure, and all the wounds healed completely with dressings (-Fig. 14). Twin B 


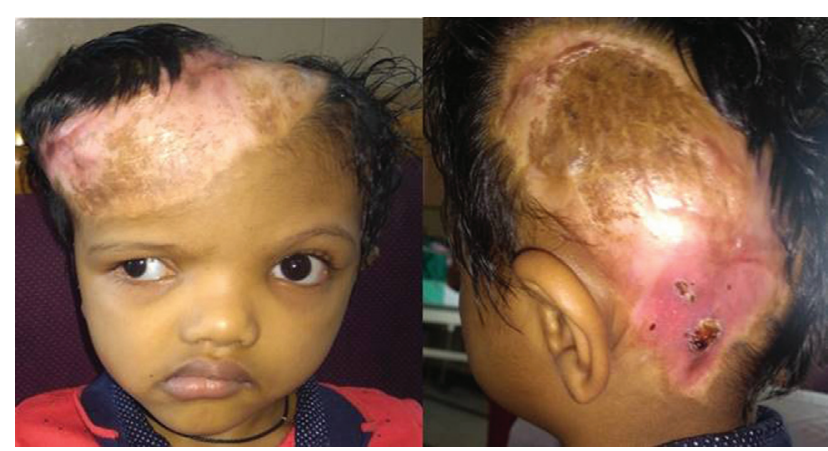

Fig. 14 Completed healed surfaces of twin J.

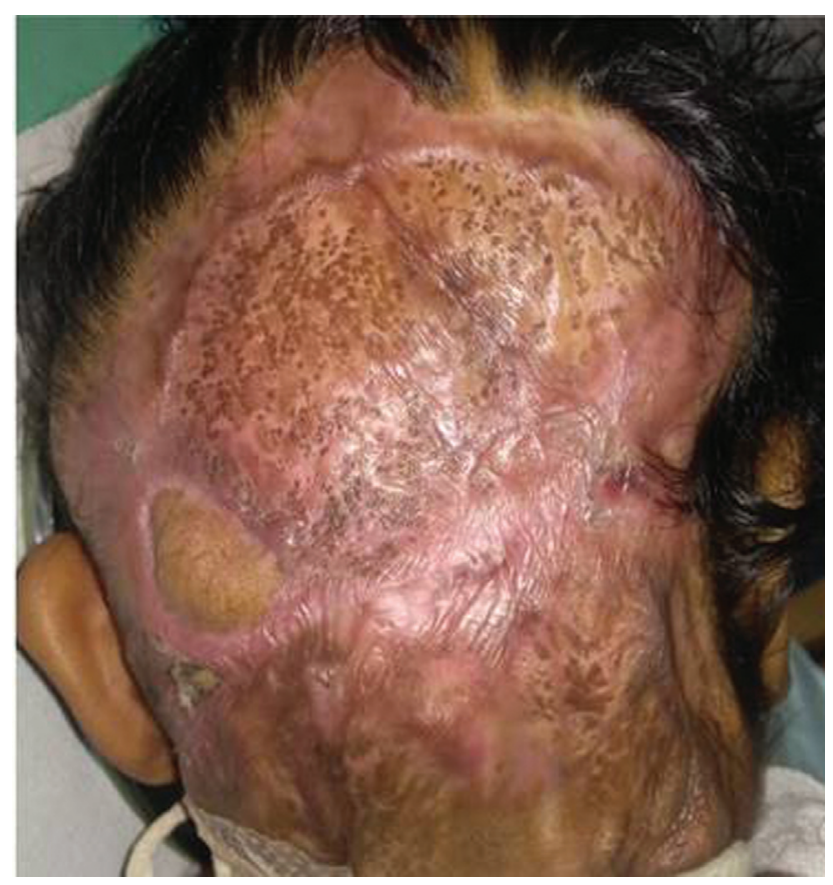

Fig. 15 Posterior healed surface of twin B.

required STSG, and all the wounds healed completely (-Fig. 15). He was an inpatient for a longer period as he required extra nursing care, physiotherapy and nutritional support as he was not able to walk or eat himself due to extensive brain tissue loss (-Fig. 16). Both the children were discharged from the rehab after about 3 years of admission.

\section{Discussion}

A thorough understanding of the conjoined anatomy and physiology coupled with meticulous planning, commitment, and coordination among the team members at every step is essential for a successful outcome in craniopagus twin separation. Due to the complexity and rarity of the case, plastic surgery teams of two institutes (AIIMS and Ganga Hospital) were involved in the planning and execution of surgical reconstruction.

A systematic review by Harvey et al studied various variables that could determine successful outcomes in craniopagus separation and found that staging the procedure

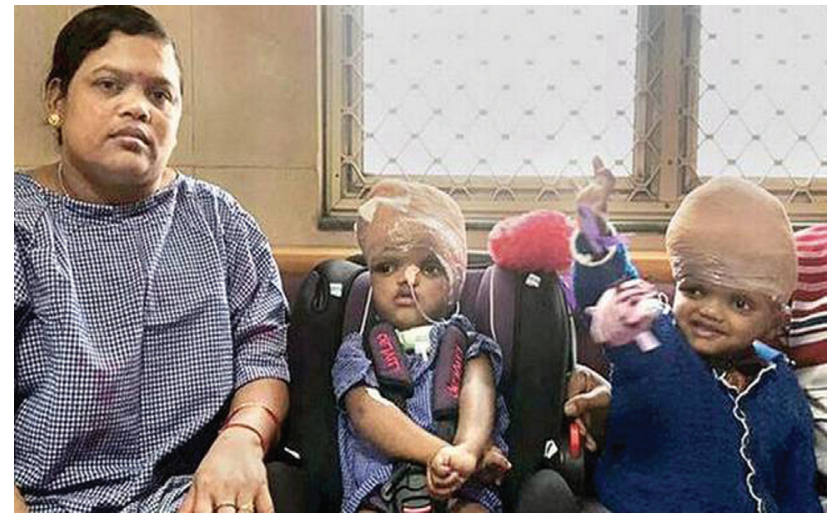

Fig. 16 The two children healthy and comfortable after separation.

did not significantly imply a successful outcome. However, when they combined the unreported and peer-reviewed cases, they found a trend toward the significance of staged procedures and successful separation. ${ }^{2}$ A staged approach is currently favored. Dunaway at the Great Ormond Street Hospital, London, is also a strong proponent of the staged approach. He described the initial two stages for venous and parenchymal separation of the twins, followed by a separate stage for tissue expansion and then the final separation. According to Dunaway, staged separation offered a more subtle approach to the venous drainage, and it would provide adequate time for the collateral circulation to take up the change in the blood flow. ${ }^{12}$ Staffenberg and Goodrich ${ }^{10}$ stated that in previous staged procedures in the literature, stages were close together and there was minimal effect on morbidity and mortality when compared with single-staged separation. They proposed multiple-staged separation with appropriate recovery time between stages to get the desired outcome. During this time, the team should be committed to very close observation and be ready for separation if needed. Staged separation is favorable from a plastic surgeon's point of view, since it offers an opportunity to introduce tissue expanders and gain extra skin for closure.

In our case, we opted for a staged procedure. The skin incision was put in a "yin yang" ${ }^{12}$ way to provide maximum exposure to our neurosurgery colleagues for craniotomy, in order to put tissue expanders in the occipital regions of both children with the same incision and also include respective superficial temporal arteries in the flaps. The neurosurgery team decided that twin $\mathrm{J}$ would be receiving the native circular sinus, and the cortical veins of twin B were disconnected from the sinus. Thus, the future skin flaps were to be planned in such a way that the child receiving the native sinus would receive more native scalp skin flap cover. The rest of the scalp was still virgin and future skin flaps could be planned, according to the postoperative course of the twins. During the first stage, two tissue expanders were placed after the conclusion of the neurosurgery part.

Tissue expansion uses the viscoelastic properties of the skin to create more skin and soft tissue when a constant stretching force is applied to the skin. ${ }^{8}$ Use of tissue expanders has become commonplace in the separation of craniopagus twins in the last two decades. ${ }^{13}$ However, the timings 
of placing tissue expanders have been variable. Goh used tissue expanders before any intracranial procedure and utilized the expanded flaps to cover the exposed brains of both the children after a long surgery. ${ }^{14} \mathrm{~A}$ similar technique was used in the Guatemala twins ${ }^{15}$ by Kawamoto and team and the Egypt twins ${ }^{16}$ by Salyer and team. However, when multiple intracranial procedures are required for more gradual venous disconnection and staged procedures, as has been advocated by many authors, 2,10,11 tissue expanders should be put at the penultimate stage. Placing tissue expanders along with an intracranial procedure in a single stage can increase the morbidity, as was also seen in our case, which leads to expander rupture. Intraoperatively instilled saline of the tissue expander would be completely indistinguishable from a subcutaneous CSF collection.

There is significant sharing of blood in craniopagus twins both in the arterial system as well as the venous system. The main reason for staged separation is that it gives time for the superficial venous system of one child to adapt to change its direction and drain preferentially to the deeper venous system. This change is seldom predictable, and a unidirectional flow can easily be established after partial venous disconnection. A similar phenomenon happened with our twins when twin B preferentially started draining toward twin J. Whatever fluid or drugs were given to twin $B$, to combat hypovolemia, was going to twin J and causing hypervolemia. Even tilting the bed did not significantly improve their hemodynamic status. Dunaway described a similar phenomenon where tipping the bed toward the oliguric child improved their physiology. ${ }^{11}$ This twin-twin transfusion has even led to renal transplantation in craniopagus twins in the past. ${ }^{17,18}$

This chronic fluid overload in twin J deteriorated his cardiac output to near $20 \%$ and forced us to plan for emergency separation 2 months before the planned separation. A combination of complications (expander related, cardiac and renal related) forced the craniopagus team for emergency separation to prevent continued cardiac overloading and subsequent cardiac failure in twin J. The scalp tissue as well as the neural tissue did not have enough time to recover from the initial surgery.

Although free flap reconstruction has been reported in the literature for scalp reconstruction, in craniopagus twins' separation, ${ }^{14}$ it was used as a secondary procedure to combat infection and improve wound healing. For immediate coverage of the defect, using microvascular-free flaps has been largely discouraged due to the large relative surface area of the calvaria in children and increased complexities related to very small vessels and long operating time. ${ }^{10,11}$ Local expanded scalp flaps along with pericranial flaps STSGs and other skin substitutes have been traditionally used to cover the exposed brain and dura in all cases. In our case, twin J's skull defect could be completely closed by using expanded scalp flaps and pericranial flaps with split skin grafts over the pericranium, which later healed in approximately 2 months without any CSF leak. The large posterior fossa defect was covered by trapezius myocutaneous flaps, a first time use in craniopagus separation. However, for posterior scalp defects and neck defects, the trapezius flap has been well-described for other indications. ${ }^{19-21}$ Unfortunately, due to prolonged triple inotropic support and intense peripheral vasoconstriction, much of the superficial part of both the flaps were lost. Management of shock by using vasopressors in patients undergoing flap surgery has the possibility of vasoconstriction-induced decrease in flap perfusion. Rat studies have shown that intraperitoneal epinephrine tends to decrease skin flap survival by causing vasoconstriction. $^{22}$

Conservative debridement was performed on twin B to prevent the brain from protruding, and cadaveric skin allograft was used as biological cover to prevent desiccation and wound dehiscence. Cadaveric allograft skin has been used in extensive burn patients where donor area is limited. Of all the skin substitutes described, skin allograft is considered the best option whenever available. ${ }^{23,24}$ It provided precious time that was required for the brain edema to subside and reasonable gliosis to form till granulation tissue occurred. To the best of our knowledge, skin allograft has been used for the first time in craniopagus separation surgery.

Repeated conservative debridements and multiple dressings were done for twin $B$, in which eventually the brain was exposed, and there was continuous CSF leak from the wound for 1 month and gradually granulation tissue appeared over the brain, which was again covered with skin allograft. After allograft rejection, the clean granulating bed over the brain was autografted, and all the wounds healed within 3 months. The brain is a very vascular tissue and can readily accept skin graft. There have been cases where skin grafts were placed directly over the brain. ${ }^{14}$ Using acellular dermis with skin autografts has also been reported by some authors. ${ }^{1}$

Both the twins improved during the 2-year stay at the institute; after separation, twin J was discharged shortly after and remained in the hospital with his parents, whereas twin B remained as inpatient for feeding issues and physiotherapy for limb spasticity. Both the twins were discharged 2 years after separation, shifted to their native state, and placed under the care of a multidisciplinary team of the state medical college

\section{Conclusion}

Plastic surgeon plays a crucial role to cover the exposed brain and bare bone left at the end of separation of the craniopagus twins. The defect is too large for any flap cover, and tissue expansion is the key. Meticulous planning of the incisions for exposure, the site of insertion of the expanders, and attention to detail during expansion are important. If the defect size exceeds than the anticipated size, emergency planning of a local flap must be done, and free flaps are usually technically not possible. In a procedure where success is defined in terms of having live children at 30 days postsurgery when both twins survive, it is considered a great tribute to the teamwork and a measure of the leadership.

Details of Earlier Presentation

The paper was presented in APSICON 2018, Lucknow, UP, India. 
44 First Successful Separation of Craniopagus Twins in India Singhal et al.

\section{Declaration}

Authors declare that consent for publication with identifiable photographs was obtained from the parents.

\section{Conflict of Interest \\ None declared.}

\section{References}

1 Spencer R. Conjoined twins: theoretical embryologic basis. Teratology 1992;45(06):591-602

2 Harvey DJ, Totonchi A, Gosain AK. Separation of craniopagus twins over the past 20 years: a systematic review of the variables that lead to successful separation. Plast Reconstr Surg 2016;138(01): 190-200

3 Boer LL, Schepens-Franke AN, Oostra RJ. Two is a crowd: two is a crowd: on the enigmatic etiopathogenesis of conjoined twinning. Clin Anat 2019;32(05):722-741

4 Walker M, Browd SR. Craniopagus twins: embryology, classification, surgical anatomy, and separation. Childs Nerv Syst 2004;20 (8-9):554-566

5 O'Connell JE. Investigation and treatment of craniopagus twins: introduction. BMJ 1964;1(5394):1333

6 O'Connell JE. Craniopagus twins: surgical anatomy and embryology and their implications. J Neurol Neurosurg Psychiatry 1976; 39(01):1-22

7 Stone JL, Goodrich JT. The craniopagus malformation: classification and implications for surgical separation. Brain 2006;129(Pt 5):1084-1095

8 Agrawal K, Agrawal S. Tissue regeneration during tissue expansion and choosing an expander. Indian J Plast Surg 2012;45(01): $7-15$

9 Gupta DK, Mahapatra AKAIIMS Team Craniopagus. Addressing the shared circumferential sinus in craniopagus conjoined twins: is venous bypass an option? World Neurosurg 2020;133:421-422

10 Staffenberg DA, Goodrich JT. Separation of craniopagus conjoined twins with a staged approach. J Craniofac Surg 2012;23(7, Suppl 1)2004-2010
11 Dunaway D, Jeelani NU. Staged separation of craniopagus twins. Semin Pediatr Surg 2015;24(05):241-248

12 Staffenberg DA. Discussion: separation of craniopagus twins over the past 20 years: a systematic review of the variables that lead to successful separation. Plast Reconstr Surg 2016;138(01):201-203

13 Heuer GG, Madsen PJ, Flanders TM, Kennedy BC, Storm PB, Taylor JA. Separation of craniopagus twins by a multidisciplinary team. $\mathrm{N}$ Engl J Med 2019;380(04):358-364

14 Goh KYC. Separation surgery for total vertical craniopagus twins. Childs Nerv Syst 2004;20(8-9):567-575

15 Frazee J, Fried I, Kawamoto H, et al. The separation of Guatemalan craniopagus twins. Childs Nerv Syst 2004;20(8-9):593-600

16 Swift DM, Weprin B, Sklar F, et al. Total vertex craniopagus with crossed venous drainage: case report of successful surgical separation. Childs Nerv Syst 2004;20(8-9):607-617

17 Rutka JT, Souweidane M, ter Brugge K, et al. Separation of craniopagus twins in the era of modern neuroimaging, interventional neuroradiology, and frameless stereotaxy. Childs Nerv Syst 2004;20(8-9):587-592

18 Klein DJ, Filler RM, Azarow KS, Geary DF. Extrauterine twin-twin transfusion affects renal function and perioperative management of conjoined twins. J Pediatr Surg 1998;33(02):354-356

19 Nakajima H, Fujino T. Island fasciocutaneous flaps of dorsal trunk and their application to myocutaneous flap. Keio J Med 1984;33 (02):59-82

20 Yang HJ, Lee DH, Kim YW, Lee SG, Cheon YW. The trapezius muscle flap: a viable alternative for posterior scalp and neck reconstruction. Arch Plast Surg 2016;43(06):529-535

21 Sen SP, Ghosh S, Nandi M, Nandi B. Trapezius myocutaneous flap for scalp defect. Indian J Plast Surg 1990;23(02):38-40

22 Krammer CW, Ibrahim RM, Hansen TG, Sørensen JA. The effects of epinephrine and dobutamine on skin flap viability in rats: a randomized double-blind placebo-controlled study. J Plast Reconstr Aesthet Surg 2015;68(01):113-119

23 Wilson D, Greenleaf G. The availability of allograft skin for large scale medical emergencies in the United States. Cell Tissue Bank 2014;15(01):35-40

24 Singh AK, Shenoy YR. Skin substitutes: an Indian perspective. Indian J Plast Surg 2012;45(02):388-395 